\title{
Desafios na escolarização da criança com altas habilidades/superdotação: um estudo de caso
}

\author{
Bruna Louzeiro de Aguiar Barros* \\ Sandra Ferraz de Castillo Dourado Freire**
}

\section{Resumo}

O estudo investiga aspectos da constituição de si de uma criança com altas habilidades/superdotação (AH/SD) no contexto da escola. Objetivou analisar o significado dos processos escolares para esse educando priorizando a dinâmica sócio-afetiva dos posicionamentos pessoais e as concepçóes de si emergentes nesse período de transição. Apresenta um estudo de caso com um menino de seis anos com AH/SD, que está no primeiro ano do ensino fundamental e atende ao programa especializado da Secretaria de Estado de Educação do Distrito Federal. Foram realizadas observaçóes e entrevistas com a criança, família e professores, privilegiando análise dialógica dos posicionamentos pessoais nas interaçôes narrativas e discursivas. A análise dos resultados sinaliza que o desenvolvimento do self se dá a partir de experiências partilhadas com o outro, tanto na escola como na família, e que, no caso da criança com AH/SD, as significações de si são de complexidade incomum e emocionalmente intensas. $\mathrm{O}$ sujeito do estudo é fascinado pela construção do conhecimento e aprecia atividades inter e multidisciplinares. A transição para o ensino fundamental despertou interesse renovado pelos conteúdos, mas mostra-se frustrado e confuso com os processos escolares. Observações das situaçōes pedagógicas e do discurso dos professores apontam que há necessidade de projetos integradores que contemplem o conhecimento em sua multiplicidade de forma lúdica e pela promoção das interaçôes sociais, especialmente com crianças com AH/SD.

Palavras-chave: Inclusão escolar; Altas habilidades/superdotação; Concepçóes dinâmicas de si.

\footnotetext{
* Pedagoga formada pela Univesidade de Brasília, Brasília, Distrito Federal, Brasil.

** Professora doutora da Univesidade de Brasília, Brasília, Distrito Federal, Brasil.
} 


\section{Schooling challenges of high talented and giffed children: a case study}

\section{Abstract}

The study investigates self development aspects of a high talented/gifted child in school. It aims at analyzing the meaning about school processes by this child giving priority to the socio-affective self positions' dynamics and the self conception emerging through the transition to the first grade. It conducts a case study with a six years old gifted boy that also attends a special education program by the Education State Secretary of Federal District, Brazil. The empirical work consisted of observation and interviews with the child, family members and teachers. The analysis design considered dialogical self positions within narratives and discursive interactions. Results show that a high talented/gifted child's self development goes through shared social experiences and individual meaning in school and family contexts. The child is fascinated by the knowledge construction, enjoys interdisciplinary and multidisciplinary activities. The transition to the elementary school increased the interests in content, but also shows frustration and confusing moods while facing schooling processes. There is a need for integrating projects that acknowledge and fulfill knowledge in its multiplicity in a playful way and by the promotion of social interactions.

Keywords: School inclusion; High talented/giftedness; Dynamic self conceptions.

\section{Introdução}

A educação especial é marcada por uma dicotomia histórica, mesmo com os avanços das políticas de inclusão (MEC/2010). Estudos continuam sinalizando que as práticas pedagógicas desconsideram as particularidades de seus educandos (MIRANDA, 2008) e que "nesta cultura, as crianças que entram e permanecem na escola devem se submeter a tarefas e recursos de ensino comuns" (MACEDO, 2005, p. 11). Situaçóes como essa afetam, especialmente, educandos com deficiência, transtornos globais do desenvolvimento e com altas habilidades ou superdotação (AH/SD). Consequentemente, devido as suas respectivas singularidades, podem ser levados ao abandono por parte do sistema educacional e tratados com desprezo em escolas com salas de aulas regulares, com ou sem integraçáo à sala de recursos.

É importante considerar que a escola e a sala de aula compreendem um "sistema construído por um conjunto de elementos - alunos, professores, conteúdos, atividades de ensino, [...] avaliaçốes etc. - que se relacionam e interagem entre si" (COLL; SOLÉ, 2004, p. 243). Ao mesmo tempo, é esse o "espaço de instituição das práticas e da constituição dos sujeitos", em que se dá a "convergência simbólica de conteúdos e práticas que circulam em várias dimensôes da cultura" (SMOLKA, 2006 apud FREIRE, 2008, p. 45). Assim, os educandos constituem seu self no decurso dos acontecimentos de açôes e práticas imersas na perspectiva da cultura dominante da sociedade (FREIRE, 2008). Se negligenciarmos a subjetividade como força motriz no desenvolvimento escolar e global dos educandos, isso vai se refletir no desenvol- 
vimento de seus talentos e habilidades superiores, em especial em se tratando de educandos com AH/SD (VIRGOLIM, 2007).

Movido por tal problemática, o presente estudo teve como objetivo geral analisar o significado dos processos escolares para o educando com AH/SD ao ingressar no primeiro ano do ensino fundamental, priorizando a dinâmica sócio-afetiva dos posicionamentos pessoais e as significaçóes de si emergentes nesse período de transição. Para o alcance de tal objetivo, realizamos um estudo de caso com um menino de seis anos buscando especificamente: (1) compreender como o educando com AH/SD constitui as concepçôes de si e o papel da escola na construção das suas perspectivas para o futuro; (2) identificar as demandas pedagógicas dos professores que trabalham no atendimento desse educando, e (3) refletir sobre as possibilidades de um trabalho pedagógico que considere as concepçóes que esse estudante têm de si, a fim de potencializar a aprendizagem escolar na construção de horizontes possíveis para o futuro de sujeitos com AH/SD. Foram realizadas observaçóes na sala de aula regular e na sala de recursos e entrevistas com a criança, família e professores, privilegiando análise dialógica dos posicionamentos pessoais nas interaçôes narrativas e discursivas.

\section{Altas habilidades/superdotação: conceituação de um termo e significação do sujeito}

Em relação à conceituação de altas habilidades/superdotação, é difícil encontrar um consenso entre os especialistas da área. E ao mesmo tempo, uma única definição tem poucas chances de compatibilizar sua abrangência, pois "muitos são os aspectos que devem ser considerados, e grandes são as dificuldades encontradas quando se busca definir o termo" (ALENCAR; FLEITH, 2001, p. 52). Mais adiante, discutimos a questáo da subjetividade da pessoa com AH/SD em desenvolvimento na perspectiva dialógica, a qual orienta este trabalho.

Inicialmente, destacamos a teoria das inteligências múltiplas de Howard Gardner e a concepçáo de superdotação dos três anéis e o modelo triádico de enriquecimento de Joseph Renzulli. Tais teorias têm sido as mais adotadas para aferir sobre a temática, pois há:

sincronia entre o conceito multidimensional que propõe a existência de oito inteligências [...] não hierarquizadas e o conceito de superdotação, entendida como a intersecção de três grupamentos de traços-habilidade acima da média, comprometimento com a tarefa e criatividade-permite propor indicadores de AH/SD em qualquer uma dessas inteligências. (FREITAS; PÉREZ, 2012, p. 18).

Há uma discussão sobre o desenvolvimento assincrônico e a intensidade das emoçóes do educando com AH/SD, demonstrando que a criança com AH/SD apresenta uma subestrutura cognitiva e emocional diferente das demais crianças náo dotadas. A criança não só pensa mentalmente dissemelhante, mas sente e percebe o mundo também de forma única. Assim, correspondem ao desenvolvimento assincrônico características não comuns no que tange ao nível de consciência, experiências de vida e percepçóes. Com esse entendimento, uma criança com AH/SD pode mostrar-se 
cognitivamente avançada e possuir uma elevada sensibilidade emocional, apresentada em suas formas variadas. Pode, em determinados momentos, agir com emoções equilibradas e, em outros, aparentar-se completamente imatura, o que pode configurar-se em um risco psicossocial (VIRGOLIM, 2007).

\section{Desenvolvimento do self em crianças com AH/SD na escola}

Consideramos o desenvolvimento do self um fenômeno eminentemente dialógico e dinâmico (FREIRE, 2008). Isso requer uma abordagem sistêmica, "dialético e desenvolvimentista, no qual os aspectos intra e interpsíquico se fazem presente, não no sentido de excluir-se, mas ao contrário, de complementar-se" (PALUDO, 2011, p. 12303). Entretanto, o senso comum sustenta o mito de que o sujeito com $\mathrm{AH} /$ SD náo precisa do outro para se desenvolver e construir autorreferências como, por exemplo, autoconceito e autoestima. Virgolim (2007), por exemplo, destaca a força motriz do autoconceito em pessoas com AH/SD no desenvolvimento das mesmas, uma vez que reflete em seus talentos e habilidades superiores. Também destaca que, ao longo da infância e adolescência, é comum haver conflitos constantes acerca das concepçóes que elas imaginam que as outras pessoas têm delas, o que pode provocar sentimentos fragmentadores ou integradores na construção do seu self.

As concepçôes que uma pessoa constrói de si estấo continuamente em desenvolvimento (MACEDO; SILVEIRA, 2012). Inspirada nos estudos do self de Willam James e de Hubert Hermans, Freire (2008) propóe o construto concepçóes dinâmicas de si (CDS) como forma de compreender a emergência da complexidade da constituição cultural, relacional, social, moral e ética do ser humano. Destaca que o ser humano somente pode ser entendido em sua constituição maior se considerar os processos culturais, de mediação, que operam ao longo de seu desenvolvimento. Ressalta a necessidade de considerar o contexto em que a "constituição de grupos sociais é concomitante ao desenvolvimento de sistemas de valores sociais e morais que regem as (inter) açôes" (FREIRE, 2008).

No presente estudo, optamos pelo construto de CDS (FREIRE, 2008) por servir como uma categoria analítica das mudanças do sistema de self a partir da identificaçáo e análise de indicadores comunicativos e metacomunicativos dos posicionamentos pessoais que são expressos na narrativa e reflexóes do sujeito e precebidos pelos outros, pois são posicionamentos que tendem a medear as interaçóes sociais. Em resumo, podemos considerar que as CDS são coconstruídas em contextos de intensa qualificação do sujeito e de sua ação; possuem significativa carga afetiva e valorativa de si; são eminentemente dinâmicas, pois as possibilidades de mudanças se dão face ao fluxo bidirecional eu-outro. Uma CDS é uma instância da construção semiótica na medida em que é, ao mesmo tempo, signo, objeto e sujeito da semiose. As CDS são plurais também dentro do sistema de self, podem ser contraditórias, sendo possível conceber a trajetória de uma CDS no diálogo com outras CDS e sua proeminência como ponto focal nas interaçóes em um determinado momento. A qualidade de uma CDS e seu status nas relações hierárquicas existentes no sistema 
estão relacionados ao grau de enraizamento afetivo e resistência à sua mudança ao longo da ontogênese.

Assim, a escola encontra-se como um dos mais importantes espaços sociais por oferecer meios concretos e simbólicos para o sujeito viver e sentir múltiplas experiências necessárias para processar significações e sentidos. A educação escolar é intencional e conduzida por professores e especialistas qualificados (COLL; SOLÉ, 2004). Nesse contexto, as CDS das crianças em escolarização ocorrem no decurso dos acontecimentos das açóes educativas e práticas pedagógicas imersas na perspectiva da cultura dominante na escola (FREIRE, 2008). Por isso, se compreendermos o fundamento dialógico do desenvolvimento psicológico da pessoa, é possível dar visibilidade a posição dinâmica e complexa da alteridade no processo da construção semiótica e reflexiva de si e, então, intervir com açóes propositivas de superação e desenvolvimento.

\section{Estudo de caso: o caso Davi}

O sujeito do estudo é Davi. À época da pesquisa, ele estava no primeiro ano do ensino fundamental em uma escola particular e frequentava um centro de atendimento especializado (sala de recursos), parte do Programa de Atendimento aos Alunos com Altas Habilidades/Superdotados, da Secretaria de Estado de Educação do Governo do Distrito Federal. Participaram também da pesquisa: Ana (34 anos), mãe do estudante; Jorge (35), pai do estudante; Laura (41), professora da sala de aula regular e Nelson (41), professor da sala de recursos. A todos os participantes foram atribuídos nomes fictícios.

A pesquisa qualitativa contou com observaçóes e entrevistas. Realizamos as observaçôes naturalistas na escola regular e na sala de recursos mediante registros em diário de campo enfatizando as açóes e interaçóes de Davi. Realizamos três entrevistas individuais com Davi, a fim de promover diálogos sobre si e saber como ele referese ao seu processo de escolarização e aprendizagem. As entrevistas foram gravadas e transcritas integralmente. As conversas fluíram, naturalmente, conforme as demandas de interesses colocados pelo educando. Durante a primeira e a segunda entrevista, Davi mostrou-se receptivo aos diálogos. Na última entrevista, mostrou-se emocionalmente mais sensível às questôes de caráter qualificativo de si mesmo, especialmente ao narrar interaçóes que envolviam incompreensão por parte das outras pessoas.

A análise das entrevistas seguiu uma abordagem interpretativa das informaçóes, tomando como base as entrevistas; as observaçôes ofereceram informaçóes contextuais dos episódios narrados para análise e interpretaçáo. Priorizamos o processo de significação das questóes emergentes no sentido de configurar as CDS predominantes, entendendo o self como sistema semiótico de enfoque sistêmico, bem como a teoria da subjetividade na perspectiva histórico-cultural. Primeiramente, identificamos, nas narrativas de Davi, episódios com carga emocional acerca dos temas relacionados à família, ambiente escolar, seus interesses para estudos, amizade, brincadeira e sobre si mesmo. Em seguida, identificamos as pessoas mais significativas nos episódios narrativos e de que forma estavam afetivamente envolvidas (direta ou indiretamente) nas 
construções subjetivas dele. Isto é, como Davi se posicionava na situação perante o outro e como ele acreditava que o outro o posicionava na relaçáo. Analisamos as qualificaçôes presentes e negociadas nas narrativas sobre suas experiências. Finalmente, nas entrevistas realizadas com os professores e a família, procuramos identificar temas e posicionamentos que tivessem relaçóes com a análise da narrativa de Davi, especialmente aos seus aspectos cognitivos e psicossociais. Na discussão a seguir, optamos por apresentar os resultados no presente simples, como forma de preservar a clareza discursiva.

\section{Como a criança com AH/SD constitui as concepções de si mesmo}

É recorrente, na narrativa de Davi, uma CDS como menino inteligente. Declara-se "sábio" quando desenha o seu cérebro e escreve ao lado a palavra sabedoria. Explica que o desenho representa sua inventividade e se posiciona satisfeito com essa representação. Entretanto, diz que não é uma criança totalmente feliz. Vejamos como ambos os posicionamentos atuam na constituição das concepçóes que Davi está construindo de si mesmo.

A CDS de inteligente é caracterizada pelo qualificativo sábio e pela ação de inventar e, por isso, tem a convicção de que vai estudar na Universidade de Brasília no futuro. A significação é coconstruída pela família pois, no cruzamento dialógico dos diferentes procedimentos empíricos, é possível relacionar posiçôes que sustentam essa CDS de Davi tanto no plano discursivo como nas trocas interpessoais. Considerando autoconceito como sendo uma característica mais ampla e geral do self, e autoestima, relacionada ao aspecto que emite juízo de si próprio (VIRGOLIM, 2007), consideramos que a CDS de inteligente está vinculada a um sentimento de aceitação, reconhecimento e estima, e que é o qualificativo mais dialogizado nas relaçóes com os adultos.

As CDS referentes a sua inteligência podem ser evidenciadas nos seguintes trechos: "eu já entendo um montáo de coisas", "é só usar um ábaco, uma calculadora... Que eu sempre levo na minha mochila... Aí resolve tudo!" e "sabe quanto tempo demorou?" De forma assertiva e segura de si, ele parece reconhecer-se como conhecedor tanto do conteúdo como do seu processo intelectual; como competente no uso de objetos culturais para alcançar os seus objetivos e a valorização da presteza e rapidez em resolver problemas ou compreender um assunto. Aqui entendemos que a rapidez pode ser um indicador que contribui para a caracterização de constituição social de sua CDS. Fatos esses se devem a dois fatores fundamentais: constatação empírica na repercussão de suas açôes e feedback oferecido pelas outras pessoas reiteradamente.

O caráter dinâmico e dialógico das CDS é dado, entre outros, pela ambiguidade intra e inter-relacional. Mesmo se tratando de uma consolidada e dominante autorreferência de alguém inteligente, nos três meses de observaçáo foi possível identificar um conflito gerado por sentimentos ambivalentes referentes às perspectivas dos outros sobre ele no que se refere à sua inteligência. Embora diante da segurança do reconhecimento de suas "capacidades", Davi anseia por ser reconhecido em outros níveis: "ainda falta concurso, e campeonato, e olimpíadas". Talvez haja angústia por ora 
ter sua inteligência reconhecida, ora se sentir rejeitado pela sua qualidade intelectual, especialmente na escola. Davi parece estar no processo de canalização cultural de valores competitivos, sinalizando que ele deve ser ganhador de um evento "oficial" para ser aceito como é. Ao mesmo tempo, percebe que há uma rejeição ou impaciência da professora Laura com relação às suas qualidades intelectuais, que se refletem no seu isolamento social na sala de aula.

É, também, recorrente na narrativa, o movimento entre polos diferentes, entre algo bom e algo ruim, entre o agradável e o desagradável, e é assim que Davi se expressa quando menciona ser uma criança "mais ou menos feliz". É uma CDS em emergência, que ainda não pode ser designada. Refere-se às relaçóes interpessoais no contexto da escola e da família. Na escola, está marcada pelo sentimento de rejeição. Entristece-se quando diz que "têm pessoas que me detestam demais". Para ele, a amizade é caracterizada por um profundo senso de respeito "sem me machucar, falar palavrão... tipo isso". Parece que ser uma pessoa sem amigos causa-lhe sofrimento. Também sente-se rejeitado e desrespeitado quando as interaçôes são marcadas por uma imposiçáo do outro ou de um lugar não digno para ele. As relaçôes coetâneas parecem processos de self conflituosos para Davi.

Sendo o self um sistema semiótico de si e as CDS o aspecto reflexivo contextualizado e em transformação, as relaçôes não podem ser vistas sem sua ancoração no tempo e espaço. A família é um contexto cultural importante para Davi e algumas referências sobre si a posicionam assim: "eu queria que minha família fosse mais animada”. Sua expressão não é de tristeza, mas cremos que mobiliza significaçóes para Davi não se sentir totalmente feliz. A palavra animação pode estar ligada a um desejo de aceitação ou reconhecimento de sua sagacidade. Aparentemente, no espaço familiar, ele gostaria de vivenciar trocas com o lado humorista do seu self. Ele vê contradiçốes e pequenos absurdos e transforma-os em ideias engraçadas em função de seu pensamento divergente, plural e polissêmico. Ele se ressente ao sinalizar que reconhece no olhar da sua mãe as exigências sociais que ela faz em função dele. Ela demonstra ter uma alta expectativa e coloca a si própria na condição de atender às demandas cognitivas do filho. E, ele só quer brincar.

Acreditamos que as CDS de Davi condizem com o self em seu nível abstrato, elaborado junto aos seus sentimentos e ao sentido subjetivo das experiências. Segundo Virgolim (2007), a formação do autoconceito da criança de seis anos caracterizase por um viés concreto, de qualidades observáveis e visíveis. O fato de Davi já tecer consideraçóes acerca de si mesmo de forma mais abstrata, pode ser compreendido na perspectiva de que as crianças com AH/SD tendem a possuir uma subestrutura cognitiva e emocional diferente no que tange ao nível de consciência, experiências de vida, percepçôes e emoçôes.

As CDS de Davi foram construídas a partir das experiências vivenciadas de maneira individual e coletiva nos contextos nos quais ele se encontra presentemente inserido. Consideraram produtivamente o olhar dos outros sociais, mas com significaçóes próprias em decorrência de suas açóes e experimentações, mobilizadas pela relação entre as dimensóes inter e intrapsicológica da subjetividade. A constituição 
das CDS mobiliza o caráter dialógico da subjetividade, promovido da relação entre as dimensōes inter e intrapsicológica de forma dinâmica, marcada pelas experiências individuais e coletivas compartilhadas com o outro (FREIRE, 2008; PALUDO, 2011). Cremos que o caso de Davi sinaliza a complexidade das CDS levando em conta como ele percebe a dinâmica de sua aprendizagem, a experiência no contexto da sala de aula regular e de recursos e o reconhecimento da família. Isso podemos confirmar nas narrativas do professor Nelson, da professora Laura, da mãe e do pai, quando reconhecem que Davi é ativo em seu processo de aprendizagem, possuindo vocabulário extenso e avançado para sua idade, persistência, boa memória e facilidade para apreender informaçóes novas e resolver problemas que exigem raciocínio lógico-dedutivo.

\section{O sentido do processo de escolarização e o papel da escola na construção das perspectivas para o futuro}

Davi demonstrou, em suas narrativas, que o processo de sua escolarização passa a ter sentido quando envolve sua paixáo em estar sempre aprendendo, bem como quando ele pode lidar com a construçáo do conhecimento de maneira multidisciplinar, explorando a sua sagacidade, tendo respeitadas as suas áreas de interesses de estudos e o ritmo de sua aprendizagem. Ele ressalta a preferência em realizar atividades mais difíceis, participar das olimpíadas de matemática, usar diversificadas estratégias para solucionar dificuldades nos estudos (como calculadora, ábaco, computador e internet). Os relatos dos professores e dos pais destacam que o sentido do processo de escolarização de Davi envolve uma energia crescente em aprender, principalmente nas áreas de matemática e biologia, atividades lúdicas, muito diálogo com outra pessoa igualmente conhecedora e uso de tecnologias educacionais dependentes de recursos elétricos na construção dos conhecimentos.

O sentido do processo de escolarização para esse educando com AH/SD dialoga com o desejo de inclusão no contexto do espaço escolar. Sob a ótica da Teoria da Subjetividade de Gonzáles Rey, a inclusão deve ser tratada como é "percebida, sentida e desejada pelos vários sujeitos da escola" (ALBUQUERQUE; MARTÍNEZ, 2012, p. 197). Compreendemos que Davi náo se sente incluído em seu processo de escolarização, pois percebe que suas reais necessidades educacionais não são priorizadas, por vezes até desrespeitadas, especialmente no que se refere a sua autonomia frente ao processo de ensino e aprendizagem. Ele menciona que não gosta da escola, porque é a professora quem escolhe o que ele deve estudar.

Assim, o sentido do processo de escolarização relaciona-se com alternativas de possibilidades educacionais diversificadas. É preciso que a aprendizagem e o desenvolvimento de habilidades superiores considerem, de forma especial, a área acadêmica e criativa-produtiva do educando. O estudo do caso de Davi possibilitou-nos aferir que criança altamente habilidosa nos anos iniciais do Ensino Fundamental apresenta expectativas esperançosas referentes ao seu processo de escolarização, e acredita que a escola de ensino regular assume papel fundamental na construção positiva das suas perspectivas de futuro. 


\section{Demandas pedagógicas e as concepções de AH/SD dos professores que trabalham no atendimento ao educando}

As especificidades do trabalho de inclusão de educandos com AH/SD foram contextualizadas no ambiente da sala de aula e na sala de recursos. A professora Laura enfatiza a necessidade de dedicaçáo e paciência, enquanto o professor Nelson menciona que o trabalho pedagógico exige envolvimento com a tarefa, criatividade, persistência e motivação. A principal dificuldade de lidar com Davi, para Laura, é a dispersão em aula e, para Nelson, a falta de recursos materiais para desenvolver atividades mais interessantes. Para a professora regente, as especificidades da aprendizagem de Davi parecem se apresentar como desafio e dificuldade no sentido de ter que atender as demandas dele para além do resto da classe e afirma que uma das principais dificuldades que ele enfrenta na escola é a "repetição". O professor Nelson demonstra "satisfação por ser responsável no desenvolvimento das potencialidades do aluno" e destaca que o grande desafio que as crianças com AH/SD enfrentam na escola é a "falta de entrosamento com os colegas e o não encontro de oportunidades para conversar sobre seus interesses com os professores e alunos".

Ambos os professores articulam, de forma recorrente, preocupaçóes em diferentes níveis. Em nível institucional, quando se referem aos recursos materiais e didáticos, e em nível da subjetividade, quando falam das questôes inter e intrapessoais no contexto da experiência escolar. Em nossa análise, consideramos que os dois níveis de preocupaçôes tem, em sua base, carência de políticas e planos de ação para a efetiva inclusão das crianças com AH/SD.

É necessário considerar a falta de aplicação adequada dos investimentos e das políticas na manutenção das salas de recursos. Entretanto, o que nos parece mais sensível são as condiçôes necessárias na formação de professores, tanto inicial quanto continuada. Quando a professora Laura afirma ser a dispersão a sua maior dificuldade em seu trabalho pedagógico, talvez esteja sinalizando incompreensão da complexidade que há por trás da "dispersão" do Davi. Parece haver uma indisposição com relação ao fato de ele relacionar constantemente uma diversidade de assuntos, hipóteses e questôes em uma tarefa que para ela é apenas para ser realizada linearmente, sem discussão, sem possiblidades de criação. Aparentemente, a participação imaginativa e criativa de Davi é uma interferência na condução da aula. É conhecido que os sujeitos com AH/SD possuem uma imaginação vivida (VIRGOLIM, 2007). Essa característica poderia ser amplamente explorada por uma abordagem interdisciplinar e não só com Davi, mas todas as crianças passariam a ter condiçôes de desenvolverem e terem seus potenciais reconhecidos (RENZULLI, 2004).

A qualidade das relaçóes sociais no contexto da experiência escolar, de alguma forma, também está vinculada à formação inadequada dos professores para lidar com processos de ensino-aprendizagem que acontecem de forma dinamizada nas interaçôes entre professor, estudantes e conteúdos (COLL \& SOLÉ, 2004), seja em sala de aula regular ou em sala de recursos. Aparentemente, o sistema escolar não atende com competência a formação continuada de seus professores, trabalhando as especificidades exigidas pela inclusão escolar e oferecendo um sistema de apoio 
didático de assistência psicopedagógica ao professor. Nem sempre as políticas e os planos de ação impactam o trabalho de base dos professores junto aos estudantes com AH/SD. É possível sinalizar, especificamente a partir desta pesquisa, certa carência de recursos psicológicos e didáticos da professora de sala de aula. Acreditamos que é preciso oferecer espaços construtivos para desenvolver a sensibilidade em lidar com os intensos sentimentos e emoçôes dos estudantes com AH/SD. Para Virgolim (2007), essa questão é imprescindível na aprendizagem escolar e no desenvolvimento de suas habilidades superiores.

\section{Possibilidades pedagógicas}

Ao relacionar a Teoria das Inteligências Múltiplas (GARDNER, 1994), das correntes teóricas para superdotação (RENZULLI, 2004) e o construto das Concepçóes Dinâmicas de Si (FREIRE, 2008), elaboramos algumas possibilidades pedagógicas para a inclusão escolar de crianças com AH/SD.

Considerando a constituição do self de Davi, suas especificidades intelectuais e das experiências relacionais, devemos promover um diálogo entre o sentido pessoal atribuído ao próprio processo de escolarizaçáo e a importância do papel da escola para o desenvolvimento de suas habilidades superiores. Os professores devem, no planejamento didático, considerar as habilidades criativo-produtivas do Davi, como: o desejo crescente em estar sempre aprendendo, utilizar o seu extenso vocabulário, a boa memória, seu prazer em dinamizar a aprendizagem pelo diálogo de forma lúdica, sua intensa capacidade de produçáo de ideias originais, em conjunto com sua vontade de se dedicar a estudos na área da matemática, tecnologia avançada, mecânica e insetos, mas, principalmente, reconhecê-lo como uma criança de seis anos de idade, com direito a se socializar e a vivenciar relaçôes afetivas entre seus pares.

Uma questão importantíssima a ser considerada nesse processo é a interação social no desenvolvimento cultural da criança. O caso de Davi ilustra como a família e os professores reconhecem, incentivam e estấo preocupados com os aspectos acadêmicos de suas habilidades. Entretanto, há uma carência fundamental na promoção de espaços sociais ricos em interação e negociação necessários ao desenvolvimento sócio-afetivo (VYGOTSKY, 2007). As CDS de Davi estâo intimamente relacionadas à açáo formativa de todos os adultos que convivem com ele (FREIRE, 2008). Percebemos que as CDS dominantes de Davi são do plano dos adultos, distante das ferramentas culturais compartilhadas com outras crianças. Isso se deve às características de inteligência superior da criança com AH/SD (VIRGOLIM, 2007). Porém, a família parece restringir as interaçóes de Davi com crianças do prédio onde mora, por exemplo. Tampouco há uma ação intencional na escola de promoção dessas relaçôes. Isso pode acarretar um déficit sociocultural no desenvolvimento de Davi, com implicaçôes no desenvolvimento afetivo-emocional.

Sabemos que é comum a educação escolar ser centrada no professor, ser diretiva, valorizar a construção linear de saberes mediante planejamento engessado sob a justificativa de atender aos conteúdos determinados nos planos de educação. Entretanto, a sala de aula apresenta um conjunto de conteúdos e práticas pedagógicas 
mediadas pela diversidade cultural, diferenças nos processos de aprendizagem e viabilizadas nas relaçôes entre professor e educando e educando e educando (COLL \& SOLLÉ, 2004). Se a escola tomar como fundamento de seus princípios educativos o caráter dialógico, dinâmico e social do desenvolvimento da subjetividade de seus educandos, poderá ela tecer possibilidades pedagógicas para potencializar a aprendizagem escolar na construçáo de horizontes possíveis para o futuro e, consequentemente, oferecer oportunidades para a criação de CDS construtivas para o seu self.

\section{Conclusão}

Ao iniciarmos este estudo, constatamos sensível escassez em estudos referentes ao desenvolvimento da subjetividade de educandos com AH/SD que permitissem entender as emoçóes, ritmos e dinâmicas de suas aprendizagens, e nada encontramos na literatura que levasse em conta o olhar dos mesmos sobre os seus processos de desenvolvimento no contexto escolar. Por isso, consideramos que este trabalho representa o início de estudos sobre a constituição das concepçóes de si com educandos com AH/SD. Futuramente, poderão ser realizadas pesquisas com educandos de diferentes idades, realidades socioculturais e níveis escolares. Bem como realizar estudos com outras crianças com AH/SD de seis anos de idade para certificar, ou não, a elaboração do self em seu nível abstrato e como vivenciam o ingresso no Ensino Fundamental.

Apoiadas pela literatura apresentada, tentamos demonstrar que o desenvolvimento da subjetividade do educando com AH/SD nos anos iniciais se constitui de forma dialética, dinâmica, contínua e relacional. Consideramos que educandos com AH/SD já possuem concepçóes de si mediadas pelas qualificaçóes construídas nas interaçôes sociais como qualquer outra criança. Entretanto, o que difere na criança do estudo é que as CDS são expressas por verbalizaçóes mais generalizadas e com cargas de emoção intensas. Consideramos que essa questão possa estar relacionada com o nível de intensidade no envolvimento e autoexigência no próprio desempenho nos assuntos que possui interesse. Também pode estar relacionada com o nível de exigência na relaçáo com o outro, especialmente com os pares, que é comumente marcada pelo forte sentimento de rejeição, no caso de Davi.

Salientamos que as demandas pedagógicas e as concepçóes de AH/SD dos professores que trabalham no atendimento ao educando estão relacionadas às políticas e planos de ação para a inclusão e à compreensão dos processos diferenciados de aprendizagens em seus aspectos sociais e psicológicos. Bem como há urgente necessidade de recursos materiais e didáticos diferenciados e investimento nos profissionais e nas condiçóes dos contextos formativos desses educandos. Cremos ser de fundamental importância a construção de projetos interdisciplinares integradores que contemplem o conhecimento em sua multiplicidade, mobilizados pelo lúdico, integrando o teórico e o prático de forma criativa e produtiva.

\section{Referências}

ALENCAR, E. M. L. S.; FLEITH, D. S. Superdotados: determinantes, educação e ajustamento. 2. ed. São Paulo: EPU, 2001. 
ALBUQUERQUE, A. P.; MARTÍNEZ, A. M. Inclusão escolar e subjetividade social da escola: relaçôes e possibilidades. In: BRANCO, A. M. C. U. de A; OLIVEIRA, M. C. S. L. de O. (Orgs.). Diversidade e cultura da paz na escola: contribuiçôes da perspectiva sociocultural. Porto Alegre: Mediação, 2012. p. 185-211.

BRASIL. Ministério da Educaçáo. Secretaria de Educação Especial. Marcos Político-Legal da Educação Especial na Perspectiva da Educação Inclusiva. Secretaria de Educação Especial. Brasília: Secretaria de Educação Especial. 2010.

COLL, C.; SOLÉ, I. Ensinar e aprender no contexto da sala de aula. 1996. In: COLL, C.; PALACIOS, J.; MARCHESI, A. (Org.). Desenvolvimento psicológico e educaçáo - Psicologia da Educação, Volume 2 (pp. 241-260). Porto Alegre: Artes Médicas, 2004.

FREIRE, S. F. C. D. Concepçóes dinâmicas de si de crianças em escolarizaçáo: uma perspectiva - dialógico desenvolvimental. Brasília, 2008. 280f. Tese (Doutorado em Psicologia). Instituto de Psicologia, Universidade de Brasília.

FREITAS, S. N.; PÉREZ, S. G. P. B. Altas habilidades/superdotaçáo: atendimento especializado. 2a. ed. Marília. 2012.

GARDNER, H. Estruturas da mente: a teoria das inteligências múltiplas. Porto Alegre: Artes Médicas, 1994.

MACEDO, L. S. R.; SILVEIRA, A. C. Self: um conceito em desenvolvimento. Paidéia (Ribeirâo Preto). 2012, vol.22, n.52, pp. 281-290. ISSN 0103-863X. Disponível em: <http://www.scielo.br/scielo.php?pid=S0103-863X2012000200014\&script=sci_arttext> Acesso em: 15 jan. 2013.

MACEDO, L. Ensaios Pedagógicos: como construir uma escola para todos? Reimpressão. Porto Alegre: Artmed, 2005.

MIRANDA, A. A. B. Educação especial no Brasil: desenvolvimento histórico. Cadernos de História da Educaçáo, Uberlandia/MG, v. 7, p. 29-44, jan./dez, 2008. Disponível em: <http://www.seer.ufu.br/index.php/che/ article/view/1880/1564> Acesso em: 18 out. 2012.

PALUDO, I. K. Subjetividade do sujeito com altas habilidades/superdotação: um ensaio sobre alteridade. In: X Congresso Nacional de Educaçáo, 2011, Curitiba. Seminário. Curitiba: Pontifica Universidade Católica do Paraná, 2011. p. 12301-12307.

RENZULLI, J. S. O que é esta coisa chamada superdotaçáo, e como a desenvolvemos? Uma retrospectiva de vinte e cinco anos. Educação. Tradução de Susana Graciela Pérez Barrera Pérez. Porto Alegre, ano XXVII, n. 1, p. 75-121, jan/abr. 2004. Disponível em: < http://redalyc.uaemex.mx/src/inicio/ArtPdfRed.jsp?iCve=84805205> Acesso em: 14 jul. 2012.

VIRGOLIN, Â. M. R. Altas habilidades/superdotaçáo: encorajando potenciais. Brasília: Ministério da Educaçáo, Secretaria de Educaçáo Especial, 2007.

VYGOTSKY, L. S. A formaçáo social da mente: o desenvolvimento dos processos psicológicos superiores. $7^{\text {a }}$. ed. São Paulo: Martins Fontes, 2007.

\section{Correspondência}

Bruna Louzeiro de Aguiar Barros - Rua 22 Norte, LT 04, Residencial Villa Lorenza, Apt. n. 201.

Águas Claras, CEP: 71916-250, Distrito Federal.

E-mail: brunalouzeiro@hotmail.com - sandra.ferraz@gmail.com

Recebido em 23 de junho de 2014

Aprovado em 22 de abril de 2015 